\title{
PARALLEL TESTING WITH CRUDE HEART EXTRACT WASSERMANN ANTIGENS*
}

\author{
BY \\ I. N. ORPWOOD PRICE and A. E. WILKINSON \\ From the Whitechapel Clinic, London
}

The antigen used in the Harrison-Wyler Wasserextract of fresh ox heart muscle, to which 1 per cent. alcoholic cholesterol is added to give a final concentration of 0.4 per cent. cholesterol. One part of the mixture is then diluted with 14 parts of normal saline, the resulting opalescent suspension being used as the antigen in the test. Richardson (1940) introduced a modification of this antigen by further diluting it with five times its volume of saline, and he claimed that this procedure enhanced both its sensitivity and its specificity. Price (1950a), using the principle of optimal proportions, has shown that the cholesterolized crude heart extract antigen can be made considerably more sensitive by using it at its optimal titre. This is an individual property of each extract, and has been found in the seven so far tested to range between 1 in 120 and 1 in 480 . When parallel quantitative tests on positive sera are made, using different batches of extract each at its optimal titre, remarkably constant endpoints are obtained. This affords a method of standardizing the performance of antigens of this type. The

* Received for publication, Oct. 26. 1951. mann technique (Wyler, 1929) is an alcoholic

consistent level of sensitivity which results is a very real advantage when the serological behaviour of patients is being observed over a prolonged period.

The results of parallel tests on six sera, using seven antigens prepared over a period of 2 years, are presented in Table I.

It can be seen that although the titres of the antigens varied from 1 in 120 to 1 in 480, they gave very uniform endpoints with these sera, the results not varying by more than one dilution. It is also evident that the antigens keep very satisfactorily for at least 2 years when stored in the dark at room temperature.

\section{Technique}

In the present investigation 4,860 sera were tested in parallel using two antigens :

(a) Batch 29 cholesterolized and diluted 1 in 15 as for the standard Harrison-Wyler technique (S antigen).

(b) The same extract, cholesterolized and used at its optimal titre of 1 in 180 (O.T. antigen).

The Whitechapel Wassermann technique as described by Price (1950b) was used with both antigens. Sera were tested in parallel on the same day. Where discrepant results were obtained with

TABLE I

RESULTS OF QUANTITATIVE SERUM TESTS WITH SEVEN DIFFERENT EXTRACTS USED AT THEIR OPTIMAL TITRES

\begin{tabular}{|c|c|c|c|c|c|c|c|c|}
\hline \multirow{2}{*}{ Extract } & \multirow{2}{*}{ Titre } & \multirow{2}{*}{$\begin{array}{c}\text { Date of } \\
\text { Preparation }\end{array}$} & \multicolumn{6}{|c|}{ Serum Number } \\
\hline & & & 18 & 20 & 35 & 48 & 54 & 68 \\
\hline $\begin{array}{l}23 \\
26 \\
28 \\
29 \\
40 \\
43 \\
44\end{array}$ & $\begin{array}{l}1-360 \\
1-120 \\
1-480 \\
1-180 \\
1-200 \\
1-320 \\
1-180\end{array}$ & $\begin{array}{r}18.5 .49 \\
8.9 .49 \\
8.11 .49 \\
23.11 .49 \\
15.11 .50 \\
4.4 .51 \\
19.7 .51\end{array}$ & $\begin{array}{l}- \\
- \\
- \\
-\end{array}$ & $\begin{array}{l} \pm 64 \\
+32 \\
+32 \\
\pm 64 \\
+32 \\
+32 \\
\pm 64\end{array}$ & $\begin{array}{l} \pm 64 \\
+32 \\
\pm 64 \\
+32 \\
+32 \\
\pm 64 \\
+32\end{array}$ & $\begin{array}{l} \pm 16 \\
\pm 16 \\
\pm 16 \\
\pm 16 \\
\pm 16 \\
\pm 16 \\
\pm 16\end{array}$ & $\begin{array}{l}+32 \\
+32 \\
\pm 64 \\
+32 \\
+32 \\
\pm 64 \\
+32\end{array}$ & $\begin{array}{l}+32 \\
+16 \\
\pm 32 \\
+16 \\
+16 \\
\pm 32 \\
\pm 32\end{array}$ \\
\hline
\end{tabular}


TABLE II

RESULTS OF COMPARATIVE TESTING OF 4,860 SERA

\begin{tabular}{|c|c|c|c|c|c|c|}
\hline \multirow{2}{*}{ Group } & \multirow{2}{*}{$\begin{array}{l}\text { Sera } \\
\text { Tested }\end{array}$} & \multicolumn{2}{|c|}{ Agreement } & \multicolumn{3}{|c|}{ Disagreement } \\
\hline & & No. & Percentage & Antigen & Total No. & Percentage \\
\hline 1. Whitechapel Clinic & 2,780 & 2,690 & $96 \cdot 7$ & $\begin{array}{r}\text { S. }+ \\
\text { O.T. }-\{2 \\
\text { S.T. }+\}\end{array}$ & 90 & $3 \cdot 27$ \\
\hline 2. London Hospital .. .. & $1,100^{*}$ & 1,092 & $99 \cdot 3$ & 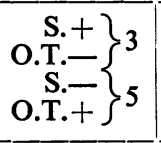 & 8 & $0 \cdot 7$ \\
\hline 3. V.D. Reference Laboratory & $980^{*}$ & 875 & $90 \cdot 3$ & $\left.\left.\begin{array}{r}\text { S. }+ \\
\text { O.T. }-\{24 \\
\text { O.T. }+\end{array}\right\} 81\right\}$ & 105 & $9 \cdot 7$ \\
\hline
\end{tabular}

* An additional five sera in Group 2 and 31 sera in Group 3 which gave anticomplementary results have been excluded from consideration.

the two antigens, tests were repeated to minimize technical errors. The sera came from three sources :

(1) 2,780 sera from patients attending the Whitechapel Clinic for investigation or treatment.

(2) 1,100 sera from patients in the London Hospital ; among these were 411 sera from antenatal patients.

(3) 980 sera sent to the Venereal Diseases Reference Laboratory (Medical Research Council). These included both sera sent for confirmatory testing and "problem" sera which had given anomalous, results in other laboratories.

The sera from the Clinic and the Hospital form a representative sample of specimens which might be sent for testing to any laboratory undertaking serological tests for syphilis. Those from the Reference Laboratory were included because it was thought that they might afford a useful indication of the relative specificity of the two antigens. The results of these tests are summarized in Table II.

\section{Discussion}

There were ninety sera in the first group (from clinic patients) which gave discordant results with the two antigens. Of the two sera reacting with the S. but not with the O.T. antigen, one came from a patient with treated syphilis and the other from a man with non-gonococcal urethritis. He was observed for 3 months during which time his serum titre with $\mathrm{S}$. antigen declined from 1 in 80 to negative. This was considered to be a non-specific reaction. No cause for it was found.

Among the 88 sera reacting only with the O.T. antigen, 76 came from 71 patients who had been treated for syphilis ; these reactions were considered to be specific. The remaining twelve sera came from ten patients who had no history or clinical evidence of syphilis. Seven of them were from patients who had gonorrhoea, one with non-gonococcal urethritis, and one who had penile warts. Five of these ten patients defaulted from observation, so that no opinion can be given as to the interpretation of the serum tests. The remaining patient was a pregnant woman who gave a series of inconclusive results in the absence of any history or clinical evidence of syphilis. Her husband was sero-negative. When the pregnancy was 7 months advanced, she was thought to have a hydatidiform mole and the uterus was evacuated. The foetus was normal and histological examination of the placenta showed no abnormality. The patient was given prophylactic penicillin (5 mega units) postoperatively. Her serum tests became negative and remained so for 12 months, when her Wassermann reaction became positive at a low titre, other tests being negative. It is thought that this patient's reactions were probably non-specific in nature ; the treatment with penicillin unfortunately obscured the position.*

It is evident from these results that the use of the antigen at its optimal titre increased the sensitivity of the test very considerably, as indicated by the 76 sera from syphilitic patients which reacted with this antigen only. It is not possible to form any definite opinion as to the specificity of the O.T. antigen, because full examination of half the patients in this group giving possible non-specific reactions was precluded by their defaulting from observation. If it is assumed that all these twelve sera gave nonspecific reactions, the incidence with the O.T. antigen in the group as a whole is 0.36 per cent.

\footnotetext{
* Since this was written a Nelson Treponemal Immobilization Test has been performed and has given a positive result. Our thanks are due to Dr. C. W. Chacko of the Wright-Fleming Institute, St. Mary's Hospital, for carrying out this test.
} 
This is thought to be an overestimate, and it is high when compared with the standard antigen which only gave one non-specific reaction in this group. Thus in the second group of sera (see below) non-specific reactions obtained with the standard Harrison-Wyler antigens were 0.27 per cent.

In the second group of sera (from hospital patients) there were three which reacted only with the standard antigen. Two of these came from patients with pneumonia and one from a man complaining of hoarseness of voice. Five sera reacted only with the O.T. antigen ; one from a pregnant woman, one from a two-year-old child with prurigo, and one from a woman who had been treated in the past with liver injections for anaemia. There was insufficient serum available to repeat tests on the remaining two sera, one from a patient with infectious hepatitis, and one from a patient whose clinical diagnosis was not known. Excluding these last two sera, as the possibility of technical error had not been removed, the incidence of nonspecific reactions with each antigen was 0.27 per cent., or, in the case of the O.T. antigen, 0.46 per cent. if the two incompletely investigated sera are assumed to have given non-specific reactions.

The evaluation of the 105 sera which gave discrepant results in the third group (specimens sent to the Reference Laboratory) does not rest on any certain basis. Of these sera, 54 came from cases of treated syphilis ; six of these reacted only with the standard antigen, and 48 with the O.T. antigen alone. These results confirm the higher specific sensitivity of the latter antigen. A further 31 sera came from patients in whom no clinical evidence of syphilis had been found; twelve of these sera reacted only with the standard antigen, and nineteen only with the O.T. antigen. No clinical details were sent with the remaining twenty sera; six reacted only with the standard antigen, and fourteen only with the O.T. antigen. If these twenty sera are excluded from the group on the grounds of insufficient information, the standard antigen gave $1 \cdot 13$ per cent. and the O.T. antigen 1.77 per cent. of positive reactions with sera from patients in whom there was no clinical evidence of syphilis. These percentages are exaggerated since two specimens of serum were examined from each of three of the patients, and three specimens from another patient. Even allowing for this factor, the incidence of presumed non-specific reactions for both antigens is high; it should be remembered, however, that these were selected sera, many of which had given anomalous results in other laboratories.
In the appraisal of an antigen used in serum tests for syphilis, three properties must be considered : specific and non-specific sensitivity, specificity, and the ease with which the antigen can be standardized so that different batches give comparable results. This last property has not received the attention which it deserves and the results so far obtained in the standardization of crude heart extract (or cardiolipin) antigens by the application of the principle of optimal proportions are encouraging. The results obtained show that the antigen gives results that are considerably more sensitive when it is used at its optimum titre than when it is used at the arbitrary dilution employed in the standard antigen. It is not easy to decide whether the advantages of this increase in sensitivity have been outweighed by a lowering of specificity. This difficulty is due to the fact that adequate investigation of the clinical condition of the patients involved is precluded by incomplete case histories and defaulting patients. It is not impossible that the seven patients with gonorrhoea whose sera reacted only with the O.T. antigen were incubating syphilis, and that their blood contained only enough reagin to react with the more sensitive antigen. The treatment with penicillin may have been enough to mask the development of clinical manifestations of the disease or even to abort it completely. It is felt that the best estimate of the relative specificity of the two antigens can be made from the incidence of non-specific reactions among the hospital group of patients. The total number of sera in this group is too small to allow more than an estimate to be made, but the standard antigen gave 0.27 per cent. non-specific results, and when it was used at its optimal titre the incidence lay between 0.27 and 0.46 per cent.

\section{Summary}

(1) 4,860 sera have been tested in parallel with standard Harrison-Wyler Wassermann antigen using the Whitechapel Wassermann technique, and with the same antigen used at its optimal titre.

(2) Use of the antigen at its optimal titre greatly increases its sensitivity. It is estimated to give between 0.27 and 0.46 per cent. non-specific reactions.

\section{REFERENCES}

Price, I. N. Orpwood (1950a). British Journal of Venerea Diseases, 26, 33.

(1950b). Ibid., 26, 172.

Richardson, G. M. (1940). Ibid., 16, 166.

Wyler, E. J. (1929). Spec. Rep. Ser. med. Res. Coun. Lond., No. 129. 